catalogue number, and every convenience should be made for the crowd and for the easy handling of the animals. Every man that is to help about the sale should know his place and be at his post that no delay may occur. Every promise made in the catalogue should be lived up to, and every guarantee fulfilled.

I might go on with this subject indefinitely, yet I feel that I have said enough. In closing I can only say, that I have been a breeder of purebred hogs for 30 years, starting at the very foot of the ladder without capital or experience, so that what little I do know about the business I have learned under adverse circumstances, and by bitter experience, yet I can say truthfully, I have never wavered for a moment in my ardor even though many times knocked and buffeted about. I have always had faith that the breeding of purebred hogs was a profitable business with no limit in extent, and, with all its ups and downs, is to me one of pleasure.

\title{
THE IDENTITY OF VARIATIONS AND MODIFICATIONS.
}

By Major Chas. E. Woodruff, of Plattsburg, N. Y., Surgeon, U. S. A.

For nearly twenty years the writer in his official duties has been cornpelled to study the human variations and modifications which disqualify for military or naval service, and for eight years he has been trying to classify these anomalies under the current theories of heredity. It was soon discovered that a degenerate generally has some anomaly or stigma, such as poor eyesight or hearing, which is a disqualifying defect, so that the accepted recruit; as a rule, is a normal man in every sense of the word. On account of this rigid physical examination, the army and navy personnel contains fewer degenerates than any other class of men. Among the rejected candidates, there is a great. field for the study of the degenerates who flock to the recruiting offices. The few who succeed in passing the examination are borderland types, and the great majority of deserters in peace times are'restless, unstable defectives. The deserter in war is always a degenerate.

In explaining the defects or stigmata of these men, it was found impossible to class them as hereditary variations, or as nontransmissible modifications, for no matter which view one takes of them, he soon comes to a contradiction of evidence. For this reason, the literature of the etiology of human degeneration is in a chaotic condition. The followers of the newer Lamarckian school of biologists find that the anomalies and the underlying condition of the nervous system, being direct results of an unusual environment, including excessive use or disuse of parts, are modifications, and are necessarily transmitted to offspring yet there is indisputable proof that, in many of the cases, they are not transmitted at all, and there is a wealth of evidence that anomalies may not be transmitted, unlikeness to parent being the rule in such families. On the other hand, the followers of the opposite biologic teachings of the later Darwinism also find that 
the anomalies do not agree with our conception of variations, but being in great part mere modifications, due to adverse conditions of the environment, are not transmissible. This class of writers is then inclined to look upon the underlying condition of the nervous system as a temporary one, sure to disappear if subsequent generations are placed in a proper environment during development; yet, in spite of all this, there is the unfortunate fact that degeneration is sometimes like a variation, known to appear in subsequent generations, and seems to be a hereditary condition, even if it is a modification in the first generation affected.

It is of the greatest importance that the matter should be settled, for the welfare of mankind is at stake. Already saciety is demanding protection from its own anomalous types, and has taken the first steps here and there in confining its incorrigible criminals for life, whether they are degenerate or not. This is such a burden, that society demands preventive means and is calling upon science for enlightenment. If these abnormalities are hereditary variations whose offspring are bound to become degenerate no matter what the environment, then society must take up some one of the numerous proposals to prevent marriage of the unfit or to sterilize them, if it is not practicable to confine them in asylums. If the condition is a nontransmissible modification due to an adverse environment or unnatural modes of living brought about by society itself, then it is a duty to compel parents to place their offspring in such a normal environment that proper development will occur, and if the parents cannot do this, then society for its own protection will do it for them, also making arrangements whereby these parents shall not produce more children which will burden the community to rear them properly.

Man is one of the best, if not the best species of living things in which to study variations and modifications because each specimen is carefully studied. The botanists have heretofore almost monopolized the field, having an organism under complete control. They have discovered that plants are easily modified by changes in environment, and that these modifications may apparently become hereditary, so there has been a remarkable revival of the century-old Lamarckian explanations of the appearance of those differences which by natural selection give rise to new types. Zoölogists, on the other hand, have until recently had much more to do with the survivors after selection has been at work, and, except in the case of some fossil remains, have not seen the variations which have perished from unfitness, and which have not been the progenitors of future types. Hence zoölogists, as a rule, have been much inclined to consider variations to be accidental, fortuitous, independent of the environment, or as just simply happening to appear without cause. When forced to express an opinion as to the cause of variations, they invariably presume some cause in the environment and thus practically place all variations in the class of modifications.

Even Weismann, who has occupied the most extreme position among biologists, in his denial of the transmission of somatic modifications, admits that his transmissible variations may be develop- 
mental results of the action on the germ plasm of some environmental cause. DeVries, who is often looked upon as a Lamarckian in his theory of mutations, but who is really a Darwinian, also explains his mutation on Lamarckian grounds-that is as results of a changed environment, such as a rapid succession of periods of reproduction. Yet he finds paradoxically, that sports or mutations are independent of the environment as they occur by the side of the parent type which remain wholly unaffected, giving rise later to many new types by mutation in other directions. This view probably follows from our ignorance of the cause which has acted on some of the specimens to produce mutations, but not upon others. It is a curious contradiction to find many other writers asserting that a hastening of the period of reproduction is itself always a result of a changed environment, hence mutations, if due to such causes, are the remote effects of the environment.

In discussing the somatic modifications due to a changed function of a part, such as its hypertrophy from excessive use or its atrophy and disappearance from disuse, botanists have had no data at all and are inclined to depart from this, the major part of the newer Lamarckian theories. The zoölogists are divided in opinion. Formerly they all inclined to the view that such acquired changes are hereditary, but there seems to be a goodly number who believe that such modifications are not transmitted to offspring at all. There is not the slightest evidence that the modifications required by a man are ever transmitted to his child, which must acquire for itself anew, and if it is so placed that it cannot acquire modifications as its parent did, it will not acquire them at all. Nevertheless, anthropologists as a rule are still governed by the older Lamarckian view and are the most reluctant of all zoölogists to acknowledge that modifications are not transmitted.

This error has taken complete possession of our educators, who almost to a man, believe that if we educate a negro a sufficient number of generations he will grow enough brains to make him equal the higher races.

The general conception of a variation is a difference from the parent, due to some inherent difference in the protoplasm of the ovum (the germ plasm of Nussbaum and Weismann) which causes that ovum to develop into something more or less different from the parent. The difference is transmissible, and the ovums of this new type will develop into a type more or less like the parent, and not into a type more or less like the grandparent. At the instant of its creation, that is, at the union of the germ and sperm cells, the ovum has the power to produce all the variations it will possess in its life. The mutation of deVries is merely an exaggerated variation.

A modification, on the other hand, is some difference acquired by the multicellular ovum later and is due to some cause in the environment. For instance, the thickening of the skin of the sole of the foot from friction is a late modification not seen in newborn infants nor in an adult whose feet have been protected. A modification is therefore not inherited, and in addition, cannot be transmitted. The most evident modification is a mutilation, and it is a matter of common 
knowledge that it is not transmitted, for no one ever heard of a man who had lost an arm or leg whose children were born minus an arm or leg. Some years ago there was a belief that a mutilation would eventually become hereditary if repeated a sufficient number of generations. In spite of the fact that scientists should never have a belief which is not based upon facts, there were many who advocated this baseless theory and it required many experiments to disprove it. We may amputate the tails of newborn mice forever, and yet subsequent mice are always born with tails, as far as our experiments prove. So it is now safe to say that no prominent scientist believes in the transmission of a mutilation.

Both variations and modifications can occur at any period of life from the moment of conception to old age. A child may be born with a variation, such as a different complexion than its parents; or it may be born with a modification, such as the scars and pits of smallpox from an intrauterine infection. Hence, the mere fact of an anomaly being congenital does not indicate that it is a hereditary variation. Likewise any difference appearing late in life, such as baldness, may be a hereditary variation and not a modification.

It should be noted, first, that we have no sure means of distinguishing a modification from a variation. It was first thought that a congenital anomaly was surely a variation, but that idea had to be dropped, as in the above-mentioned scars of smallpox from an intrauterine infection; likewise an anomaly appearing later in life might be a variation or a modification, according to the time of the action of the cause. Consequently, we find that it is apt to be uncertain whether a given anomaly is a hereditary variation or an acquired modification. Many anomalies which have been considered variations are doubtless due to causes acting long after birth, and there is quite as apt to be variations which are now considered to be acquired modifications due to late-acting unknown causes.

It is a remarkable fact that in anthropologic literature there are many instances in which degenerates with well marked stigmata have been photographed and studied as normal variations, whereas they were modifications due to some exceptional cause in the environment. Degenerates are figured among the types in Ripley's Racial Geography of Europe, and it is astounding that an anthropologist studying our Filipinos should have actually pictured the degenerates in the prisons as normal variations of the Malay. Quite a few are types modified by disease or other adversities, just as among our own degenerates.

Now, in applying these first principles to the differences among the men of any one racial type, whether due to degeneration or other causes, we meet so many contradictions that it is necessary to go back and examine our premises. The first patent fact is that the dividing line between variations and modifications is artificial. As stated before, every biologist knows that a variation must have a cause. Results are never causeless. It seems remarkable, then, that there should arise a belief that if the cause acts upon the germ and sperm cells before their union, the result is a transmissible variation, but if it acts upon the resulting ovum a few minutes later, it is a nontrans- 
missible modification. For instance, we know that if food is scanty the organism is dwarfed and that the condition is not hereditary, but that subsequent generations are full size if the proper food is supplied. It has been proved that shortness of stature of certain races is due to poor food, and that where they are better fed the children grow larger than the parents, even if the ancestors have been of short stature for many generations. What right then have we to assert that a changed food supply to the germ plasm can produce a hereditary variation, while a changed food supply to the ovum a trifle later will produce a nontransmissible modification?

Professor Bateson, in a late address, described variations as inherent and not something imposed, and he deplores the confounding of all divergences from type into one heterogeneous heap under the name of variations. He thinks that there are qualitative differences, either permanent or temporary, as to size, number of parts, chemistry, and all other characters usually considered specific differences. To sort out these differences into variations and modifications seems and is a hopeless task, and it is the opposite task of the advocates of orthoplasy who are to determine when a difference shall cease to be called an imposed modification and shall be called an inherent variation.

On the other hand, Prof. W. E. Castle, ${ }^{1}$ Professor of Zoölogy, Harvard, states that variations are the transitory results of varying conditions of food, temperature, moisture, light, etc.; that is, he uses the word variation as others use the word modification. With that curious inconsistency which characterizes all these bootless discussions, he states that a mutation has an internal origin and is wholly independent of the environment. Mutations being nothing more than marked variations, are probably due to causes which acted very early in the life of the ovum, though they might sometimes be due to late acting causes. Professor Wheeler ${ }^{1}$ states that there is no explanation of the origin of mutations, deVries' theory merely referring them to some inherent tendency of the germ to act abnormally. Yet Eimer asserts that mutations are due to external causes.

Dr. G. Adlerz has attempted to prove that variations are in great part the result of abundant food, and that this is the reason why wellfed domestic anmials vary so much more, both actually and relatively, than wild animals. He thinks that if wild animals are equally wellfed, they will vary as much as domestic animals, and he has considerable data that they do vary greatly in those years when they are numerous and have abundant food. Th. Eimer, and many other experimenters, have produced differences by varying the food and other means such as heat, cold, etc., and yet they assert that these are acquired characters which are transmissible and are not variations at all.

Professor Standfus, of Zurich, Switzerland, has so modified butterflies by subjecting the eggs, larvæ or pupæ to various temperatures that northern or southern species have been produced, and old species now rare or extinct have also appeared. This shows con-

${ }^{1}$ Science, April 7, 1905. 
clusively that what we call specific characters are mere results of the action of the environing forces; that is, inherent variations are really acquired modifications.

In our efforts then, to explain heredity, we have actually created two classes which do not exist. No matter at what period of development a cause acts upon the protoplasm, whether before the union of the sperm and germ cells or after the birth of the ovum months later, it merely modifies the organism, and the modification may not appear in the next generation at all if the cause does not act again.

In the effects of poisonings of the developing organism, there is a wealth of data on this point. "It has now been quite decisively determined that very many human anomalies are due to poison circulating in the mother's blood during pregnancy. In tuberculosis, for instance, there is apt to be serious interference with normal detvelopment and many anomalies are traced back to tuberculous mothers. Maternal alcoholism is another very potent cause of anomalies. In the case of paternal alcoholism, there are less reliable data, for the only way it can affect the fetus is through the protoplasm of the spermatozoid. There is much literature wasted upon the alleged degenerate products of a drunken intercourse, whereas we know that the actual spermatozoids ejected at this occasion may have been stored up for some days in the vesicles behind the bladder, uninfluenced by the alcohol. We do know that drunken fathers have far more degenerate children than the sober ones, but we are far from able to decide how much of this is due to the alcohol itself or to the defective physique caused by the alcohol, or to the underlying condition of the nervous system, which has caused the paternal alcoholism.

In an article on pathologic heredity, Dr. Alfred Gornon ${ }^{1}$ very accurately shows the trend of medical opinion on the subject of the influence of the environment. It is clearly pointed out that the harmful agents, such as poisons of alcohol, syphilis, tuberculosis and lead, have a powerful influence in modifying the germ or sperm cells and diverting them from their normal course of development, and, therefore, a great deal of abnormality is not inherited at all. As the deleterious agents act mostly upon susceptible tissue-the nervous system -it is in that system that we find so many stigmata of this harm. $\mathrm{He}$ distinctly calls it degeneration, and shows how it arises in the environment. He calls particular attention to the harm of alcoholic excess.

M. Charrin ${ }^{2}$ recounts experiments, which go a long way toward explaining the apparent heredity of certain cases where one organ is weak or diseased in several generations. He believes that there is a transmission of poisons from the mother to the fetus, and that these have a selective action on the particular organ diseased. Gravid goats were experimented with by injecting emulsions of liver tissue. The kids born were apparently normal, except the liver, which was reduced to a pulp. He thinks that toxins from other organs, say the lungs, likewise affect the lung of the fetus. Here we have a clear

'New York Medical Journal, March 25, 1905.

'La Semaine Médicale, December 17, 1902. 
case of a modification by poisons, which sppears in every generation unly as long as the cause appears. Likewise, the anomalies due to alcohol may not be hereditary, unless the cause is repeated. Monstrous forms of developing chicks can be produced at will, through mechanical interference or poisonings, and are clearly modifications which differ in no essential from the minor differences which we call variations.

Charles Féré's wonderful work in this direction has shown that almost every form of anomaly which afflicts man, can be experimentally produced in the lower animals.

There is also a tendency at present to deny the hereditary nature of all diseases, a conclusion to which John Hunter arrived over a century ago. A bad physique is inherited and it may not become diseased as the parents' did, but in some other way. In all these cases the diseases are modifications, due to causes in the environment, and do not follow our conception of a variation at all.

In the degenerate, the underlying nervous condition which we call instability, must have a cause somewhere, if we trace back such neurotic families, we are sure to come to the normal in a few generations. Hence, the neurotic line arose from a normal one through some adversity of the environment, and, though degeneration itself, is thus a modification acquired by one generation, yet it may be handed down as though it were hereditary. To believe it is hereditary, we must either prove that it is variation without environmental cause or that acquired modifications are hereditary, and both of these are yet to be proved. The explanation of the difficulty is suggested by those neurotic lines which do return to the normal; that is, degenerates can have normal children, and there is a wealth of data in proof. The condition is not always hereditary, but follows the law of modifications, which appear in every generation in which the cause acts.

To explain, we might take the extreme case of mutilations, as in the experiments to produce tailless mice. As long as the cause exists - the experimenter with his knife to clip the newborn broods-we will have generations of tailless mice, but as soon as the cause ceases the mice remain normal. Likewise as long as the causes of nervous instability exist, just that long will the condition appear in subsequent generations as though it were hereditary, but upon removal of the causes, the line becomes normal. Experiments in this line in rearing the children of the slums in proper homes are already yielding magnificent results, even in cases where degraded parentage would have led us to believe the children would surely turn out bad, even under proper rearing.

And yet we are bewildered by the contrary reports, which describe children born of vicious parents, adopted as infants by respectable people, then given, the best rearing possible, but who subsequently go wrong in a manner similar to their parents. I have been told of an unpublished case, where a foundling adopted by a clergyman went directly from the parsonage to a house of prostitution when she was 17. One explanation of these cases is that, at birth the organ- 
ism is already too far from the normal to be restored. The above child, if reared by its mother, might not have lived to be 17 .

Botanists are constantly at work varying the environment of a plant to produce modifications, which promptly return to the normal in a few generations or even in one generation if the original environment is restored. Some of our best fruits are merely modified growths, kept up by grafting and impossible of transmission to offspring, for the seeds may not produce the kind of fruit from which they were obtained. The main work of advanced botanists seems to be to find out the exact changes in the environment which have caused new desirable modifications and then advise agriculturists how to continue that special environment with its unknown causes. Foreign wheats planted in Hungary assume the peculiarities of Hungarian wheats-a cleair case of the action of the environment upon the developing organism.

Eimer and the many other zoölogists who have produced new modifications artificially or have found them produced by nature, and who have asserted that these changes are hereditary, have not shown that the causes ceased to act in the subsequent generations. Literature is full of cases of these new forms, but we are no more correct in asserting that they are permanent after the cause is removed, than we would be to assert that the weakened condition of attenuated bacteria is permanent because a few generations are still weakened after they are restored to a proper environment. It takes time to reach the normal, and the attenuated condition remains for many generations of bacteria, so that the virulence is not restored at once and an infected animal does not die for a long period compared to the time should it be infected with the normal variety. The same may be said to occur in other plants. It is the "habit of growth" which Adami uses to explain atypic cell growths.

DeVries and others show that reversion to mediocrity is the rule, and that even species are said to revert now and then, though of course more rarely. Surely this all indicates that temporary causes have been at work. Permanent species would then seem to be the results of permanent causes as a rule.

Darwin suspected that there was a periodicity about the appearance of variations and de Vries asserts that periodicity is a rule-that is, there is a tendency for a while to breed true to type and then suddenly in a generation there are marked variations or mutations which if fitted for survival, or at least are not harmful, are naturally selected and a new species arises by a jump instead of by slow degrees. It is reasonable to suggest that these sudden jumps are really due to suddenly acting causes, which we know can occur in man as well as in plants. Quetelet's law of variations show that they follow mathematic probabilities, that is, the further they are removed from the average the less numerous they are, so that their number and degree can be calculated with fair accuracy.

The whole theory that mutations are not due to environmental causes must be held sub judice until we prove that the cause once acting on one generation can effect all subsequent generations. We are 
more likely to find out that in such new permanent types there has been a repetition of the special causes in each generation, and that return to the parent type will occur sooner or later after the special causes are removed.

It is but a step to apply these ideas to all variations and modifications. A variation is merely a repeated modification due to some permanent change in the environment of the developing protoplasm or the germ plasm before conception. A modification is then a variation in the soma which is due to a temporary change in the environment. The two are identical. Neither is hereditary unless the causes are repeated, and paradoxically each is hereditary, that is, each appears generation after generation as long as the cause exists. If the germ plasm has been modified, then we can expect the anomaly to appear in one or a few generations after the cause is removed, or just long enough for the proper environment to move the organism back to its groove.

The far-reaching results of this conception should need no comment. The great problem of heredity, upon which there is a library of literature, resolves itself into the simple result of causes acting in each generation. An organism repeats the life history of its parent only so long as it has the same environment as the parent had. With unchanging environment the protoplasm is the same, and organisms breed true for ever, because the living protoplasm reacts to the same causes in the same way every generation. If a new force appears, that is, if the environment changes, the organism changes, or reacts to a new combination, and is modified into a form different from the parent form. The natural selection of a new form, if better fitted than other forms, follows as a matter of course. Thus, evolution of species depends upon changes in the environment which produce modified forms of existing species for natural selection to work upon. It is not haphazard, but all are the definite results of new forces in the environment. The problem for biologists is now to determine definitely the cause of the variations which are being produced under our observation and experiment, such as difference in food, air, water, light, heat, exercise, strains, etc.

The great objection to the theory of selection seems to be that it does not explain why variations occur, but this is no objection at all. Natural selection has nothing to do with originating the differences from which it selects. If it is generally acknowledged that these differences are duly caused by some new element in the environment, and without the slightest necessary relation to their utility, the whole matter is logical. If not harmful, they may survive, and this clears up that serious enigma-that many characters are apparently useless. They exist on sufferance.

There is a remarkable tendency of the more recent students of heredity to look upon the protoplasm of a developing germ cell as a definite chemic substance which is a mere inert machine reacting to the forces of the environment.

The molecule of protoplasm is complex and is unstable, like nitrogen compounds in general, being sensitive to forces acting upon it. 
If the environment is unchanged it behaves as ancestors behaved, and we have, therefore, always spoken of the wonderful power of heredity in the sense of great stability. Weismann even speaks of an "organic inertia" which keeps organism in the ancestral groove, producing parts, for instance, hundreds of generations after they have become useless. Then we have paradoxically spoken of the germ plasm as so exceedingly unstable as to be easily modified by slight changes in the environment. We should introduce a new term and speak of the protoplasm as reliable, that is, it can be relied upon to react to the forces the same way in every generation.

The enormous size of a molecule of protoplasm also explains the ease with which it can be modified. Professor Lodge speaks of molecules of hundreds of thousands of atoms, existing in groups, the aggregate possessing attributes not found in any one group. A cluster of a million millions of atoms is just visible under the microscope, so that it is possible for enormous molecules to exist and still be beyond our ability to see them; yet it is not at all unlikely that there are other larger groupings which act as one substance and may be actually seen. These surely are very unstable, and must give rise to modifications as a rule and not as an exception.

If a cause acts for several generations, then we have a real transient heredity, which is the term best describing those degenerate lines which return to the normal when the proper environment is restored. They have their analogy in the modified bacteria of the laboratory, organisms whose natural environment cannot be duplicated in the culture media and incubator, and which gradually change in obedience to these new forces, even to the extent of losing all pathogenic power. This condition is transient, for full virulence can be restored by passing them through a susceptible animal. As far as we now are able to determine we have never produced in the laboratory a new species of bacteria, except in this sense. There is a yeast, to be sure, which is said to be a new form thus produced, but we are not at all sure that it is not a mutation form like those of de Vries, due to a constantly acting cause, and sure to revert upon withdrawal of the cause.

I have been informed that there is also Roux's sporeless modifcation of the anthrax bacillus, which was produced by adding to the media minute amounts of such disinfectants as carbolic acid, and which continued sporeless after it was returned to the ordinary media. Whether or not it will return to the normal eventually, when its normal environment is restored is another matter. It may be now adjusted to the laboratory media and remain modified permanently just as our garden vegetables and fruits will occasionally produce a variety which will continue. Such persistences do not negative the law that new viarieties tend to revert to the old form when the causes which produced them are not repeated.

There is a possibility also, as suggested by Adami- of Montreal, that the protoplasm itself may be modified by a new cause into a chemic form, which is able to maintain itself in the original environment after the new cause has been removed. It will then be a per- 
manent variety and, indeed, in this way a great deal of organic evolution can be explained. But the ordinary modifications, such as in the domesticated plants, are not necessarily accompanied by such chemic changes, and reversion is the rule.

It has recently been said that organisms seek or even make their own environments. ${ }^{1}$ For instance, the white ants construct tunnels for shelter from light. Man also needs shelter and clothing, as he is otherwise unprotected. Likewise protoplasm after being changed by causes in the environment may remain permanently changed and survive by seeking a new environment or new set of forces to which it can properly react-that is its modifications can be permanent, though the constant tendency is to return to the former state when its environment is restored. With this reservation "heredity is the sum of all past experiences" (Luther Burbank).

When a bacterium divides into two, it is practically the same organism in two pieces instead of one-bicellular. Each part can scarcely be said to inherit from the mother cell for it is the mother cell, and possesses all of the qualities of the ancestors. It inherits in the same way that a piece of ice inherits the qualities of the block of ice from which it is broken. Hence variations in unicellular organisms are impossible-each can be modified, and when it divides into two, its modifications persist, of course. In the laboratory, each generation is modified, and in the course of some scores or hundreds of generations, the sum total of all the tiny modifications of each generation is the modified or attenuated organism.

It is proper to apply the same reasoning to a multicellular organism-man for instance. When the germ cell is split off, it is part of the parent, possessing all the attributes of the part from which it has split. If the parent has been so modified as to change this part, it will react to old forces in a new way or be further modified, so that degeneration or any other change is a modification. If tuberculosis has poisoned every cell, somatic or generative, then the germ cell which is split off to enter the uterus carries with it this modification: In this sense, inherent variations are impossible.

There is a gradual movement of scientific opinion to the view that life itself is nothing but an ability to maintain one's chemic composition, analogous at least to a crystal's ability to maintain itself and grow by absorbing materials. Living protoplasm is a chemic molecule capable of absorbing mother molecules and converting them into itself and maintaining its own composition. When it is so changed chemically that it cannot do this, it is dead. Cell death is then a chemic change - a fatal modification due to the environment. We are tending to abandon the old idea that dead and living protoplasms are chemically identical and that a vital principle has departed at death. Pathologists know that there is a decided difference between a living cell and a necrosed one.

Somatic, or body, death is another matter, it is merely a loss of coöperation-inability to continue team work-and may occur, indeed

${ }^{1}$ Prof. Wm. Wheeler, Science, April 7, 1905. 
does occur, when the vast majority of cells are still alive, and some of these cells continue to be alive for hours, or even days, after somatic death and in the lower forms of life each may give rise to a new organism after the death of the old.

Among multicellular organisms somatic death is really nothing but the discarding of a part which was used for a while in preserving the germ plasm and nourishing it, but which is no longer of use after the offspring are well started. It is uneconomical for the body to live longer. Its death, then, is necessarily a result of evolution and is beneficent and desirable. It is unnatural in the immortal unicellular organism and is always a tragedy, a result of starvation or other adversity. Life of a multicellular organism lasts just as long as it is necessary to provide for the continuance of the species. Longevity is then solely a matter of selection in certain species, to secure ulitmate survival of the species.

The recent discussions of the various states of dead matter throw considerable light on the behavior of living matter. Guillaume, ${ }^{1}$ in an article on "The Physics of Solid Bodies According to Modern Ideas," shows that there are only two states of matter, crystal and amorphous, and that the latter is usually described as solid, liquid or gaseous, though there is no distinction between these states whatever. $\mathrm{He}$ states that "solids are in perpetual motion toward a state of equilibrium, which they sometimes reach and from which they never recede unless the surrounding conditions are changed. This adaptation of solid matter is a profound and suggestive phenomenon; it is the rudimentary image of the adaptation of living beings; it constitutes a kind of inferior life that has been unsuspected hitherto, but that can no longer be neglected by the attentive observer." These physical discoveries add one more fact to the accumulating mass, showing that there is no difference between the quick and the dead, except a chemic one, for both act in obedience to impinging forces.

The laws of inertia of dead matter have been shown to apply to live cells also, that is, they are inert unless acted on by forces, and after started to activity, they possess a real momentum or inertia of motion, continuing the activity after the stimulus is removed. If the cell is so placed that it cannot function, its energies are spent in the direction of cell division; that is, the habit of growth takes the place of the habit of work. The cell inherits this acquired character or modification. Adami, ${ }^{2}$ of Montreal, uses these facts in explaining tumor growth, although he believes that vegetative cell activities, such as cell divisions, are of intrinsic origin and automatic.

If this modern view of protoplasm is correct, then variations cannot be inherent in the sense of being independent of environmental causes, for every chemic substance is inert and cannot behave differently at one time from what it did at another to the same forces, nor can it act without forces, nor act the same if the forces are changed. If we restrict the word inherent to some change in the protoplasm

'La Nature, Paris, 1905.

'British Medical Journal, March 16, 1901. 
itself as a result of the environment, so that it now behaves differently to the same forces which acted on parental protoplasm in prior generations, then we conceive of a new chemic substance, a modified form of some prior existing substance. It did not come into existence by its own inherent power, but was produced by the environment, in like manner to the production of new substances in the laboratory. In other words, protoplasm is an inert chemic substance, and, though it can be modified into a new form, yet it has no inherent power to vary without a caise. Its alleged inherent variations are modifications impressed upon it.

The most profound result of a recognition of the identity of variations and modifications will be the cessation, through compromise, of the warfare between the two great bodies of biologists, the Lamarckians and Darwinians-a warfare which has been kept up for over a generation and which has engaged the energies of some of the ablest and most brilliant men of the past half century. If one of these schools is correct the other is wrong, and it is not probable that a body of such able men can be wholly wrong. The history of other scientific controversies which have been compromised shows that each side is partly correct and partly wrong and that each had facts to work upon, but that there were unknown conditions which prevented each side from understanding the significance of its own facts. Each side interpreted its facts wrongly and built up an untenable theory.

For instance, botanists were divided into two hostile camps, one of which claimed that no plants could utilize the free nitrogen of the air, but required the combined nitrogen of compounds in the soil, while the other asserted that free nitrogen was a food for plants. Each side had facts, which apparently proved its theory. Then came the discovery that certain bacteria in the roots were the means of absorbing free nitrogen from the air and delivering the compounds to the plants, so that paradoxically the plant did and did not get its nitrogen from the air. The controversy had resulted because of incomplete knowledge.

Likewise, there were two opposing schools of biologists-one followed Liebig, who taught that fermentation was due to certain dead nitrogenous bodies; while the other followed Pasteur, who apparently proved that fermentation was due to the life activities of minute organisms. Here also it was incomplete knowledge, and there was complete harmony established by the discovery that fermentation was due to a dead nitrogenous ferment excreted by the living organism. Both sides were right and both were wrong.

Similarly, both Lamarckians and Darwinians can be right and both wrong, for there are as yet some unknown facts which rrevent a compromise. Each side of the argument is still unproved, and each set of advocates seems unable to supply the missing links which will end the controversy. Perhaps the present assertion of the identity of variations and modifications may be a help in ending an unseemly discussion which has markedly checked the advance of pathology and particularly checked the science of antbropology; and most of all, what we might call pathologic anthropology. 
Every biologist who attacks the problem gets nearer to the central truth, no matter from what side he approaches it, so that the trend of all these new ideas is toward this central fact of the identity of variations and modifications. Indeed, many scientists have just fallen short of grasping the central idea. They have advanced a long way from the other trenches captured by Darwin, who, from that place of restrictive view, thought at one time that "the variability of a species is independent of environment."

Dr. Henry C. Cowles, ${ }^{1}$ in a paper read before Section G, American Association for the Advancement of Science, 1903, comes very near to the point when he says of the Darwinian, Lamarckian and mutation theories: "It seems as if all three theories of evolution, and perhaps others, yet unborn, are quite tenable, and that the problem of adaptation is not necessarily to be associated with any particular theory of evolution."

The new theory of organic selection or orthoplasy, independently thought out by Baldwin, Osborn and Morgan, is a partial compromise. They have all discovered the old fact that organisms which have been modified so that they are better fitted for the environment, are selected for survival. But they think that this keeps the species alive while waiting for identical variations due to other causes, or causeless. The theory is really useless, for if modifications can keep a species in existence once, they can do it forever, and the appearance of variations is unnecessary. This whole theory would be discarded if it is recognized that these modifications due to one cause, differ in no respects from the variations due to other causes-that is, both are results of environmental causes.

There is really no insuperable difficulty in accounting for all organic evolution upon the basis of the reappearance of modifications in each generation, but growing more and more marked and elaborate with a continuance of the causes, just as in the case of the attenuation of bacteria. Herbert Spencer worked along this line, in his explanation of the evolution of horns, from a primitive exostosis and hypertrophy of skin epithelium from friction and injuries due to fighting with the head. He did not find it necessary to eall in variations as in orthoplasy, but he marred his explanation by the unproved assumption that these early modifications became hereditary at once without other causes. So he was drifting toward the right solution and though he did not quite reach it, he was on the opposite side from the authors of orthoplasy. What we are after now are the causes of the reappearance of this primitive epithelial hypertrophy without the original cause, though it were hereditary. Orthoplasy merely says it simply happens to come as a variation, and of course this is unthinkable, for it must have causes. Undoubtedly such a modification is due to a combination of many causes, not one only. Many things must combine, proper food supply, proper blood supply, proper enlargement of blood vessels, local irritation in early life, indeed a whole host of causes, and it is very evident that the selected animals for a

'Science, June 10, 1904. 
long, long time, hundreds of generations, will be only those in which all these causes converge, together with all the other causes of other physical changes of neck and body and skull which have accompanied the primitive horns. The action of all these causes without the friction and injury and local irritation, may sometimes cause the hypertrophy. If this is a variation-call it such-then orthoplasy is the process which has taken place. Nevertheless, the variation is due to causes acting on germ and soma, otherwise:than in the earliest hornless generations, and is in fact a modification after all.

Weismann, in his attempts to account for variations independent of environment has evolved the very complete theory of amphimixis based upon the new form of protoplasm which must result from the union of the two sexes. He asserts that sexual reproduction was evolved to produce variations, yet the best explanation of the origin of sex is through a senility or exhaustion of the protoplasm after a certain number of hundreds or thousands or millions of divisions as the case may be, and the survival of only those-which by a mutual cannibalism or autophagy were rejuvenated thereby. The exhaustion seems to be 'due to lack of nutrition or its sameness, indeed, in many organisms which reproduce assexually or by budding, it is possible to cause sexual reproduction by a reduction of the food. Unicellular organisms may be made to coalesce from the same cause. We can well conclude, then, that it is a chemic change like a step toward death, which is complete inability to react to forces.

Though autophagy is a theory having many objectionable features, its persistence shows that the tendency of biology is not to court a prior design in nature to create variations, but that they came as a result of new causes.

This whole theory of amphimixis is not acceptable, Professor Jaekel even having announced that the tendency of sexual union is to obliterate extreme variátions-it is a leveler and not a maker of variations. Explanations of Mendel's law are tending to the view that an organism may be descended from only one of its parents, the other having had no influence whatever except in "rejuvenating" the germ plasm, so that amphimixis is being gradually dropped as an explanation of variations.

It is probably this inability to account for variations which kept Virchow so long opposed to evolution. He asserted that all anomalies were pathologic modifications. According to this view were it not for such adversities of the environment all the individuals of the species would be identical.

The orthogenesis of Eimer is at basis nothing but repeated modifications as in our attenuated bacteria. The epitasis, of Jaekel, is a reversion to modified embryonic form-or arrest of development from some cause, and metakinesis (cenogenetic modifications of the embryologists) is a profound modification of fetal tissues not possible in the adult tissue. Indeed in all theories of heredity including those of Haeckel, we see the constant tendency to look to the environment for the causes of the anomalies, and we retrace our steps to the original 
conclusion of the Lamarckians that the causes of heredity are mechanical; physical and chemical.

The latest and best opinion as to the cause of human anomalies is found in Dr. J. W. Ballantyne's monumental works on "Antenatal Pathology." He finds the only reasonable explanations in purely material causes, such as poisons, and perhaps traumatisms. $\mathrm{He}$ utterly rejects any such explanation as an inherent tendency of the ovums to produce monsters. The modern and sane way of looking at these unhappy results will lead in time to the discovery of the causes and then their removal will benefit the race, but nothing will be done if we consider them to be causeless variations.

Modern explanations of inheritance are tending to the view that the environment causes all the differences between the individuals; indeed, an article on this topic by Adami ${ }^{1}$ contains much in the line of the present argument and which can be interpreted as proofs of the identity of variations and modifications.

These newer ideas are also breaking down the old distinction between heredity and variation, which have heretofore always been considered to be very strong opposing forces, one a powerful momentum tending to keep the organism in the ancestral groove, and the other a side force, tending to push it out. There are really no such forces at all. Heredity is a convenient term, like "cold," which does not express any entity at all. It merely means that when the environment acting on the ovum has been practically the same as that acting upon the parent in its development, the results are identical. Variation is a convenient expression for what always happens; that is, the environment which is composed of so many thousands of factors, each changing daily, hourly or from second to second, never can be exactly like the ancestral environment. As before explained, we might substitute the words, chemic reliability, for heredity and variation.

It will no doubt, be difficult to disabuse our minds of the idea that heredity is a force in itself, and different from the chemic affinities of the protoplasm, but if is it distinctly understood that the word merely stands for the power to react, as the parent reacted to identical forces, there is no objection to the use of the term. Organisms, then, inherit qualities or powers of reaction, just as a piece of ice inherits the chemic qualities of the block from which it is broken. We might say that heredity is the power to do as the parents did, and, naturally, the results attained are not necessarily alike in each generation.

There will be considerable objection to this view of heredity as a convenient term, but it will disappear if we will recognize that it merely means that the new ovum is a piece of the old one, and has the same chemic composition. If the old ovum has been modified, then the new one receives or inherits this modification.

It was once thought that variations occurred in an infinite number of directions, and that there was a wealth of choice for natural selection. Eimer and others show that this is not true but that varia-

'British Medical Journal, June 1, 1901. 
tions appear in only a few definite directions, as we would presume from the definite character of the chemic composition of the protoplasm. Quetelet proved that they occur, in degree and number, according to the law of probability, just exactly as the probabilities of the occurrence of the forces of the ever-changing environment.

Though botanists may have plants under careful control, yet the factors causing a new variation are so numerous that it is practically impossible to determine what has caused it. Hence, after a new variety has originated under cultivation and is then isolated and established, it not infrequently happens that if an accident destroys all the plants, it is found impossible to recreate the variety. This is not proof that the variety was causeless, but proof that we are far from knowing what the causes were.

On account of the enormous number of factors of the environment acting upon an ovum, it is not to be expected that any two can develop alike, and Professor Dwight," of Harvard, says that "the student of variations is oppressed by their multiplicity."

Professor L. H. Bailey, in a paper read before the American Philosophical Society, May 1, 1896 (See Proceedings, or Smithsonian Reports, 1897), fully explains the universal law of unlikeness. That is, all the differences between organisms are due to external stimuli: "Variations are as definite as the changes in the environment, which determine and control their existence." He quotes H. S. Williams (Geological Biology) that "mutability is the normal law of organic action." "The differences arise as a result of every impinging forcesoil, weather, climate, food, training, conflict with fellows, the strain and stress of wind and wave, and insect visitors-as a complex resultant of many antecedent external forces, the effects of crossing; and also as the result of the accumulated force of mere growth. . . ." Surely likeness can hardly be possible. When conditions are widely various, as in cultivated plants, variations are very numerous and marked.

In other words, likeness to parent is practically impossible. Like does not produce like, unless the conditions are identical. Bailey quotes Darwin, who clearly stated that variations were due to even extremely slight changes of any.kind in the conditions of life, excess of nutriment being a most efficient cause. Plants, such as potatoes are brought to a high state of cultivation and produce large tubers, but the moment we omit the causative factors there is reversion, and the high-bred types disappear. Instead of the phrase "survival of the fittest," Bailey uses the one "survival of the unlike," to emphasize the unlikeness of individuals and the fact that it is due to this that some are better adjusted to the environment than the previous generation.

De Vries, then, has discovered nothing new in his theory that a species may arise by a leap and bound, his assumption is that all species originate in this way. The variations selected by nature may be of any grade from the almost imperceptible to the very marked or

'Science, April 7, 1905. 
sport-like. The true position is best stated by Duggar": "It may even be assumed that there is a complete series between continuous (minute) variations and discontinuous (marked) variations." That is, according as the new causes are weak or powerful will the unlikeness of the offspring to parent be an almost imperceptible variation or a mutation or sport. As marked causes are rare, so are marked results, according to Quetelet's law; hence mutations do not often appear. When enormous, numbers are taken, as in Burbank's work, there are more of the mutations, though their proportion is the same.

It may happen in plants that different individuals will be subjected to identical or nearly'identical new causes at different places or times, and that there may thus be, according to de Vries, a dual or multiple origin of species by mutation. Dr. Charles A. White, of the Smithsonian Institute, reports the same phenomenon in his experiments with tomatoes, and moreover that these species may revert to a more feral type in one year by removal to a tropic climate-or whenever the factors which forced them into existence are no longer operative. $^{2}$

Similarity of environment may also evolve similarity of types of man in widely separated places, for instance, the river tribe of Leccos or Leggos, in the upper Amazen, very markedly resembles the equally aquatic Malays. ${ }^{3}$ They are branches of the same stem but have wandered into similar tropical environments. Indeed, it is an axiom of archæology that similar environments produce similar civilizations-man always reacts to the same forces in the same way.

The great contention as to the heredity of sports will disappear. One side claims great prepotency for them, while others claim that such human anomalies as. might be considered sports are not hereditary at all, being mere modifications of an unstable or degenerated organism which is easily modified by a cause harmless to the normal. Great mental power for instance is very apt to be a possession of but one generation, though it generally arises in good or prominent families. Sports or exceptional characters are due to exceptional causes.

The labored explanations of Mendel's law are also apt to be cleared up by an application of this idea of the reflex action of the protoplasmic molecule to the forces acting upon it. Even the contradictory speculations as to the origin of life can be harmonized. The molecule of protoplasm has undoubtedly undergone vast changes in the way of increasing size and complexity, and if we trace it back in imagination we come to a time when it was a very simple chemic substance reacting to an environment vastly different from the present. At this point all scientific philosophers, even Haeckel, drop the idea of a gradual evolution, and insist that in the primitive earth this chemical then suddenly became alive. Such abandonment of the idea of a gradual evolution and the substitution of a cataclysm is inconsistent. Evolution was going on before this time as a result of modifying forces and the ancestor of the living protoplasm was just

'Science, June 23, 1905.

'Popular Science Monthly, June, 1905.

'See C. J. Post, Harper's, May, 1905. 
as much alive. It is impossible to come to any other conclusion, then, than that there never has been a creation of life. The primitive chemic substances in the primitive earth were alive in the exact sense that modern protoplasm is alive, and, like protoplasm, they were being constantly modified by new forces of an ever-changing environment until they became what we might all modern protoplasm. Anything in the nature of an inherent variation of this early substance independent of the environment is scarcely thinkable.

Physicists are now talking of the evolution of matter, its birth, life and death. They point to the nebulas consisting of hydrogen only and to other nebulas in which other elements progressively appear as though evolved from the same "corpuscles" or "electrons" which formed the hydrogen atom. Then as age progresses, more and more complex substances form. So that protoplasm is but a final stage of evolution from a primitive "protyle" of which all matter is formed through external forces. A very complete synopsis of the newer ideas of matter is found in a paper by Gustav le Bon (the 1903 Smithsonian report). Prof. A. Dastre, of the Sorbonne, in an article "The Life of Matter" (1902, Smithsonian repart) even goes to the length of asserting that all the essential vital attributes which distinguish living from dead, are really possessed by all kinds of matter.

It is thus seen that while one set of philosophers has proved that all matter, whether mineral, vegetable, or animal, is dead, another set has proved that it is all alive. It is merely an unwise use of unsuitable terms, for they all mean the same thing. Multicellular organisms "do not have in themselves, by a mysterious spontaneity without example in the rest of nature, the capricious principle which sets them in motion. Vital spontaneity, so readily admitted by persons ignorant of biology, is disproved by all the history of the science. Every vital manifestation is a response to a stimulation, a provoked phenomenon. It is not necessary to say that it is the same with inanimate bodies, since that is precisely in what consists the great principle of the inertia of matter. It is plain that it is also as applicable to living as to inanimate matter" (Dastre). How is it possible, then, to conceive of a variation as anything else than a modification due to the environment, and always due to some cause which may not have acted in the prior generation, or may have acted in all prior ones.

These quotations show how easy it is to account for the strange actions of certain culture media under the influence of radium-collections of matter which Prof. J. B. Burke, of Cambridge, their discoverer, has unwisely called "radiobes" as though they were alive. They are mere results of the forces of the radium corpuscles, acting on dead matter, but they are interesting as they closely imitate the action of microbes. We can reflexly presume that identical phenomena in living bacteria are likewise due to external forces. The growth of crystals has actually been called a living phenomenon, and the growth of bacteria a dead one-how modern philosophers are confounding the quick and the dead! Prof. George H. Darwin, son of the great Darwin, professor of Geologic Sciences, and president of the British Association for the Advancement of Science, in his recent South 
African address, has even applied the law of selection or survival of the fittest to the whole inorganic world. Biologists are appropriating the laws of physics and physicists those of biology.

It is curious how the idea of the gradual evolution of life and the related idea that what we now call life is merely the present form of an evolution which has been going on since the whole solar system was a nebula, are constantly cropping up in modern scientific works. The latest is the book, "The New Knowledge," by Robert K. Duncan, professor of chemistry in Washington and Jefferson University. On p. 213 he discusses this same point after proving that all forms of matier at present existing, are merely different groupings of corpuscles or electrons resulting from changes of cosmic temperature, and says: "The great law of continuity forbids us to assume that life suddenly made its appearance out of nothing, and tells us that we - must look for the element of life in the very elements of matter, for the potentiality of life should exist in every atom." That is every molecule of every kind of matter, every atom in the molecule, and every corpuscle of the atom is as much alive as the huge molecule of protoplasm. Life never originated, but has always existed in more or less complex forms. It is evident then that the creation of life is merely the creation of a molecule of protoplasm and might be done in the laboratory if we knew how - a very big if, by the way. This leads to the final conception that, "The universe is God in one phase of Him and it possesses His attributes of eternal duration."

It was once thought that protoplasm was identical in all cells, ancient as well as modern, but there is much in favor of the view that only cells of identical function and form have identical protoplasm. All other cells are different, and this almost infinite diversity is perfectly possible, for such a molecule of an enormous number of atoms is capable of arrangements of these atoms in an almost infinite variety.

Dr. Victor C. Vaughan, ${ }^{1}$ of Ann Arbor, Mich., thinks that every cell is a distinct chemic compound, its molecule as distinct as any other chemic molecule, and that cell activity is impaired or changed by any alteration of the molecule, rearrangement of the groups of atoms in the cell or the introduction of abnormal groups.

So that no two cells can be expected to react to equal forces alike. Likewise, in tracing protoplasm back, it existed in simpler and simpler forms, until we find it a mere nitrogen gaseous compound, in the primitive hot atmosphere, reacting to the environment like its modern descendent, and just as much alive, though having no inherent power to change itself.

Regeneration of lost parts, is explained by Chas. S. Minot as due to a formative power present in all cells, a force which grows less with senescence and differentiation. It is greatest in the undifferentiated or embryonic cell having a large nucleus, but little cell plasm, a condition which is also called rejuvenation. In some. organisms, the somatic cells have lost so little of this power that the whole organism. can be grown from a group of cells taken from any part-say, leaf,

Medical Record, May 27, 1905. 
branch, stem or root. But all this can just as well be explained on the assumption that there are actual chemic changes in the senile or differentiated cell, which prevent it reacting to forces, as the embryonic cell does. Indeed, Professor Wm. A. Stechell, of the University of California, is reported to have proved that the regeneration of certain marine plants is wholly due to the action of external forces.

In regard to human differences from a hypothetic mean in any type, therè can be no doubt that they are all modifications, due to newly-acting causes in the environment. Those differences, which are occupying the attention of criminologists, alienists and pathologists, and which are due to an unstable or degenerate organism, are all modifications and examples of transient heredity, repeated every generation in which the causes are repeated. Even those alleged variations from which new types arise by selection during migration to new climates or during changes of climate, are likewise modifications repeated as long as the causes act, just as in attenuating bacteria.

The improvement of the race cannot possibly be carried on by the selection of types for breeding, as in the case of domestic animals. We cannot treat ourselves as domestic animals, for the selected are the selectors. In addition, we are not concerned with perpetuating variations, but with remedying modifications, due to the environment. Hence, all future efforts of this kind must take the direction of removing deleterious causes, improving the housing and surroundings of the poor, and placing slum children in proper homes. Experience shows that these means are effective in causing the organism to grow properly, even though it should have been somewhat damaged as early as at conception, and during the nine months of uterine life while it was subjected to maternal poisons. Of course some of these cases are already so damaged by the time of birth that nothing can be done for them.

Truancy in school children has been declared by Dr. Cronin, of the New York Health Department, to be due to physical defects and that such cases naturally drift into crime in later years. He thinks that this degradation can be lessened by improving the physical condition of the children. It is a fine recognition of the physical basis of abnormal acts in childhood, before habits or training in evil can have done much damage. ${ }^{1}$ We also know then only a few criminals -less than half-are born so. The greater number are made criminals in boyhood. Similarly the insane, in the majority of cases, are people who were born somewhat unstable perhaps, but whose brains would have remained healthy were it not for undue adversities, strains or poisons. Drunkenness, feeble mentality, and all the other anomalies have their causes too, and are not necessarily inheritances at all.

Return to the normal is then almost a universal rule in all organisms, if the environment is restored. It applies to man as well as to potatoes. The law fully explains why it is that there may be perfectly normal offspring from parents who are quite degenerate. The environment of this particular ovum may not have contained in-

${ }^{1}$ American Medicine, June 17, 1905. 
jurious forces. This is one of the best deductions to be made from this modern study of variations. We must drop the old Calvinistic belief in the preordained degeneration of the offspring of degenerates. Degeneration is a modification which is not necessarily transmitted. The outlook for the uplifting of the lower classes is therefore not so bad after all. We can well afford to be optimists.

The data upon which these conclusions are based, are in a mass of notes entirely too voluminous to even epitomize here, but the general conclusions may benefit those who are attacking from some other direction this annoying subject of heredity. The student of human variations or modifications will find himself in a maze of contradictions if he attempts to explain them by any present theory of heredity and he will be compelled to come to the conclusion that variations and modifications are really the same, each due to causes, neither inherent, and each hereditary only in the sense that it reappears when the causes are repeated.

The present attitude of biologists is well exemplified by O. F. Cook: "No amount of argument can rehabilitate Darwin's first theory of the developmental process, that the environment causes variations and then selects the desirable changes. This view was abandoned by Darwin himself, and is now held in its original logical integrity by very few working biologists, the noninheritance of acquired characters having rendered it untenable." It is quite likely nevertheless that the biologists will be compelled to come around to Darwin's original conception when they accept the proof that variations and modifications are identical.

Cook also quotes the two different ways in which to look upon heredity as an inherent force or a resultant of the environmental forces. ". . . The law of heredity, would, if nothing interfered, keep the descendants perfectly true to the physical characters of their ancestors; they would breed true and be exactly alike" (Cowes). "Were it possible for growth to take place under absolutely constant external influences, variations would not occur" (Weismann). But if we will only consider the protoplasm to be a complex inert machine, both quotations are perfectly clear, they are the expression of the fact that the law of heredity is really a law of chemic reliability to react always the same to the same forces, and to behave differently to different forces.

It is high time that the medical profession should cut loose from the biologic Capalets and Montagues whose quarrel has been so harmful to the development of pathology. It is time for us to cry "a plague o' both your houses," and leave them to their unseemly contentions. We can rest assured that the present partisans will remain partisans until death claims them, and that the quarrel will go on for another generation, so that we must in self-defense disown them both. Anyhow, the physician who studies heredity in man is far more apt to come to safe conclusions than the biologist who studies 
potatoes or primroses; and if we wish to progress we must leave them alone, taking only the facts they find. Adami pertinently says that there are pathologic states needing explanation which the biologist never sees, but which physicians see every day.

The nearest approach to the true solution of the relative value of variations and modifications is found in a popular article by Dr. P. Chalmers Mitchell": "The eggs or germinal masses, take from their parents, of which they were part, the power to respond in similar ways to similar external forces, and children resemble their parents, in so far as the external forces operating on their initial material resemble those which went to the making of their parents. It is necessary to realize that the effect of these forces is ephemeral, and that it has to be reproduced in each generation; . . ." This whole article, indeed ("The making of Modern Races") is a proof of the identity of variations and modifications, and should be taken to heart by every man who is working to check or stop the production of our degenerate classes. The medical profession, being daily and hourly occupied with the study of modifications of this one species of animal, is in a position of authority with power to stop the old biologic quarrel, and must do it in the interests of the etiology of diseases and deformities and the uplifting of the race. The anomalies are neither due to inherent wickedness of the germ plasm, nor are they inscrutable acts of God, but they are due to definite physical causes. The offspring of normal people are not foreordained to be normal-nor are the children of degenerates necessarily damned. Pessimism has no place in this matter.

\section{'N. A. Review, October, 1904.}


